\title{
Effect of prophylactic salpingectomy on ovarian function in premenopausal women in tertiary referral center
}

\author{
Tamer M. Abdel Dayem*, Amira M. Badawy
}

Department of Obstetrics and Gynecology, University of Alexandria, Egypt

Received: 21 July 2017

Accepted: 22 August 2017

\section{*Correspondence:}

Dr. Tamer M. Abdel Dayem,

E-mail: tmdaeim@gmail.com

Copyright: (C) the author(s), publisher and licensee Medip Academy. This is an open-access article distributed under the terms of the Creative Commons Attribution Non-Commercial License, which permits unrestricted non-commercial use, distribution, and reproduction in any medium, provided the original work is properly cited.

\begin{abstract}
Background: Epithelial ovarian cancers (EOCs) are the most common cause of death from gynaecological malignancy. Serous ovarian carcinomas represent $(68 \%)$ of Epithelial ovarian cancers, they are further divided into low-grade (type I) and high-grade (type II) serous ovarian carcinomas. There has been increasing evidence that fallopian tubes are considered the most important site of origin of pelvic high grade serous carcinoma. Salpingectomy is thought to be effective in reducing ovarian cancer risk in the future and prolonging average life expectancy, however, there are some concerns regarding ovarian function after elective salpingectomy in premenopausal women. The current study was carried out to assess the effect of salpingectomy on ovarian function in premenopausal women. Methods: 60 premenopausal cases were recruited and subjected to open abdominal hysterectomy without oophorectomy (for benign indications). Included cases were below 45 years, with documented active ovarian functions. Cases with genital malignancy, ovarian gross pathology and suspected or known ovarian failure were excluded. Cases were randomly allocated to one of two groups; group-A (where salpingectomy was performed), and group-B (where salpingectomy was not done). For all patients, ovarian functions were assessed prior operation, and at one and three months after operation using serum anti-Mullarian hormone (AMH) as well as early follicular antral follicular count (AFC), serum follicle stimulating hormone (FSH) and serum oestradiol (E2).

Results: The mean pre-operative AFC, AMH, FSH, and E2 levels showed no significant changes after operation at one and three months postoperative follow up in both studied groups, denoting preserved ovarian function in both groups.

Conclusions: Prophylactic salpingectomy is a safe and simple procedure that has no effect on ovarian reserve or function when performed in premenopausal women.
\end{abstract}

Keywords: Hysterectomy, Ovarian cancer, Ovarian reserve, Ovarian function, Premenopausal women, Prophylactic salpingectomy

\section{INTRODUCTION}

Ovarian cancer is a leading cause for mortality in females. ${ }^{1}$ Epithelial ovarian tumours are the most common type [68-70\%] of ovarian malignancy. ${ }^{2}$ Recently, a new classification of ovarian cancer in two different types of cancer has been introduced, where type II ovarian tumours (including the so called High-Grade Serous Cancer, HGSC) are considered the most frequently diagnosed, aggressive, genetically instable and often disseminated kind of disease. ${ }^{3}$ One of the more important finding in last decade of gynaecologic oncology is the confirmed theory that types II tumours derive from the epithelium of the Fallopian tube, whereas clear cell and endometrioid tumours derive from endometrial tissue that migrate to the ovary by retrograde menstruation. ${ }^{4}$ At present investigative efforts that are aimed at reducing the incidence of, and mortality from 
pelvic (non-endometrial) serous carcinomas should be focused on the fallopian tube, as the current state of evidence indicates that this is their site of origin in most cases, particularly because all previous attempts for screening programs could not be successfully implemented. 2,5

Therefore, careful and well-designed clinical trials for pelvic serous carcinoma prevention by removal of fallopian tubes or their fimbriated ends are justified and should be conducted. ${ }^{5}$ It is currently recommended to perform prophylactic salpingectomy during hysterectomy for benign lesions [e.g. fibromyoma or endometrial hyperplasia without atypia] which is still a common procedure. $^{6-7}$

However, there are some concerns regarding ovarian hormonal function after elective salpingectomy in premenopausal women. Diminution of serum oestradiol accelerates osteoporosis, atherosclerosis and the occurrence of cardiovascular complications. ${ }^{8}$

Ovarian functions and response to induction of ovulation has been previously studied in cases which underwent laparoscopic salpingectomy for ectopic pregnancy or hydrosalpinx. ${ }^{9}$

This study aimed at assessing ovarian function in premenopausal women who underwent prophylactic salpingectomy during abdominal hysterectomy for benign lesions.

\section{METHODS}

The current prospective observational study was conducted from the $1^{\text {st }}$ of April 2016 to the $1^{\text {st }}$ of December of the same year. The study was performed after taking the permission from the institutional ethical committee in accordance with the ethical standards of the responsible committee on human experimentation (institutional) and with the Helsinki Declaration of 1975 that was revised in $2000 .^{10}$

\section{Patient selection}

Sixty patients were primarily selected among those who were admitted to the gyne-oncology department of Alexandria University Maternity Hospital (El-Shatby Maternity University Hospital), -a tertiary referral centre for more than 10 million women at the North of Egypt-. These patients were planned for hysterectomy due to benign indications (as multiple leiomyomata, adenomyosis, and endometrial hyperplasia) mostly causing abnormal uterine bleeding with failed medical treatment.

Recruited cases were below age of 45 with active ovarian functions. Older age groups were excluded due to the possibility of reduced ovarian reserve and function. Cases with genital malignancy, prior chemo- or radiotherapy, pre-mature ovarian failure, or previous removal of one ovary, or tube or both were also excluded.

\section{Procedures}

After proper history taking, an informed written consent was obtained from all participants. Cases were then subjected to thorough general, abdominal, and local pelvic examination, followed by pre-anaesthetic check-up and routine investigations, such as complete blood count (CBC) test, random blood sugar level, liver and renal function tests and coagulation profile.

Within few weeks prior operation serum ovarian functions were evaluated by measuring serum antiMullarian hormone (AMH) as well as antral follicular count (AFC), serum follicle stimulating hormone (FSH) and serum oestradiol (E2). AFC, FSH, and E2 were assessed on day 2 or 3 of menses. In cases of irregular uterine bleeding where the start of menses cannot be determined, they were measured at any time of cycle regarding that transvaginal ultrasound showed no dominant follicles bilaterally.

Patients were divided into two groups, randomized by computer-generated numbers; group-A (included 30 cases) who underwent prophylactic salpingectectomy during the procedure of hysterectomy, and group-B (included 30 cases) who did not.

All hysterectomies were performed through laparotomy, using Pfannenstiel incision. After transfection of round ligaments bilaterally, the Fallopian tubes in group-A were removed by cutting the mesosalpinx using either monoor bi-polar electrosurgical resection, starting from the fimbrial ends medially towards the uterine ends.

The ovaries were carefully handled and resection was close to the tubes to avoid attenuation or injury of ovarian blood vessels. Thereafter, the remaining steps of hysterectomy were done. In five cases one ovary was removed intra-operatively due to gross pathology or accidental injury of ovarian vessels, these cases were excluded from the study, and replaced by other cases fulfilling the inclusion and exclusion criteria. All surgeries were performed by a senior consultant of the gyne-oncology unit.

After operation, CBC was repeated, then serial transvaginal ultrasound scans were performed to determine the early follicular phase after one and three months of hysterectomy, and repeat evaluation of ovarian functions was done measuring AFC, serum AMH, FSH and E2.

\section{Outcomes}

Primary outcome was to assess the change in ovarian function and reserve after operation. Other outcomes included; the operative time, any operative complications 
of nausea and vomiting during the first 24 hours after operation.

\section{Statistical analysis}

The Data were collected and entered to the computer. Statistical analysis was done using Statistical Package for Social Sciences (SPSS/version 20) software. The normal distribution of continuous variables was evaluated using the Kolmogrov-Smirnov test. Since continuous variables resulted in normal distribution, data were expressed as mean and standard deviation (SD).

Continuous variables were analyzed using the independent samples t-test, or the paired t-test for repeated measurements as appropriate. To compare between the three interval times ANOVA test was used. P-value of 0.05 was used as a threshold for defining difference as statistically significant.

\section{RESULTS}

After discriminating for inclusion/exclusion criteria, we selected 30 premenopausal women for prophylactic salpingectomy $(\mathrm{Group}=\mathrm{A})$ and of other 30 patients submitted without prophylactic salpingectomy (GroupB). As detailed in Table 1, there was no significant difference between the two groups for age, anthropometric characteristics, parity and operative time $(p>0.05)$.

Table 1: Comparison between the two studied groups regarding the basic characteristic feature and operative time.

\begin{tabular}{|c|c|c|c|}
\hline & $\begin{array}{l}\text { Group-A } \\
\text { with } \\
\text { salpingectomy } \\
\mathbf{n}=\mathbf{3 0}\end{array}$ & $\begin{array}{l}\text { Group-B } \\
\text { without } \\
\text { salpingectomy } \\
\mathrm{n}=\mathbf{3 0}\end{array}$ & $\mathbf{P}$ \\
\hline \multicolumn{4}{|l|}{ Age } \\
\hline Range & $36-44$ & $35-45$ & \multirow{2}{*}{$\begin{array}{l}0.074 \\
N S\end{array}$} \\
\hline Mean \pm S.D. & $41.63 \pm 2.22$ & $40.67 \pm 2.87$ & \\
\hline \multicolumn{4}{|l|}{ BMI } \\
\hline Range & $22.7-34.1$ & $22.3-34.7$ & \multirow{2}{*}{$\begin{array}{l}0.158 \\
N S\end{array}$} \\
\hline Mean \pm S.D. & $28.10 \pm 3.90$ & $29.07 \pm 3.58$ & \\
\hline \multicolumn{4}{|l|}{ Parity } \\
\hline Range & $0-6$ & $0-5$ & \multirow{2}{*}{$\begin{array}{l}0.156 \\
N S\end{array}$} \\
\hline Mean \pm S.D. & $3.13 \pm 1.43$ & $2.70 \pm 1.84$ & \\
\hline \multicolumn{4}{|c|}{ Operative time } \\
\hline Range & $45-143$ & $50-140$ & \multirow{2}{*}{$\begin{array}{l}0.118 \\
N S\end{array}$} \\
\hline Mean \pm S.D. & $84.50 \pm 18.15$ & $92.33 \pm 30.93$ & \\
\hline
\end{tabular}

BMI= body mass index. S.D.: Standard Deviation. NS: not statistically significant $(\mathrm{p}>0.05)$.

As shown in Table 2, there was no significant difference between the two groups regarding pre-operative and postoperative haemoglobin levels.

The mean pre-operative AFC was comparable between the two groups $(p=0.405)$.
After one and three month's post-operative follow up, results showed no significant changes among each group, and comparison between the two groups showed no significant differences as well, (Table 3 ).

Table 2: Haemoglobin levels in the two studied groups before and after operation.

\begin{tabular}{|c|c|c|c|}
\hline & $\begin{array}{l}\text { Group-A } \\
\text { with } \\
\text { salpingectomy } \\
\mathbf{n}=\mathbf{3 0}\end{array}$ & $\begin{array}{l}\text { Group-B } \\
\text { without } \\
\text { salpingectomy } \\
\mathrm{n}=\mathbf{3 0}\end{array}$ & $\mathbf{P 1}$ \\
\hline \multicolumn{4}{|c|}{ Pre-operative Hb (gm/dL) } \\
\hline Range & $10.4-13$ & $10.5-13$ & 0.139 \\
\hline Mean \pm S.D. & $11.52 \pm 0.64$ & $11.73 \pm 0.83$ & NS \\
\hline \multicolumn{4}{|c|}{ Post-operative Hb (gm/dL) } \\
\hline Range & $10.4-12.5$ & $10.5-12.7$ & $0.409 \mathrm{NS}$ \\
\hline Mean \pm S.D. & $11.47 \pm 0.52$ & $11.51 \pm 0.70$ & \\
\hline $\mathrm{P} 2$ & $0.103 \mathrm{NS}$ & $0.098 \mathrm{NS}$ & \\
\hline
\end{tabular}

Hb: Haemoglobin level, S.D.: Standard Deviation, NS: not statistically significant ( $p>0.05), P 1$ : comparison between the two groups at the same time, P2: comparison between preoperative and post-operative level in the same group.

Table 3: Comparison between the two studied groups regarding AFC pre-operatively and at different periods of follow up.

\begin{tabular}{|c|c|c|c|c|}
\hline & & $\begin{array}{l}\text { Group-A } \\
\text { with } \\
\text { salpingectomy } \\
\mathrm{n}=\mathbf{3 0}\end{array}$ & $\begin{array}{l}\text { Group-B } \\
\text { without } \\
\text { salpingectomy } \\
\mathrm{n}=\mathbf{3 0}\end{array}$ & P1 \\
\hline \multirow{10}{*}{ 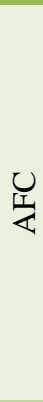 } & \multicolumn{4}{|c|}{ Pre-operative } \\
\hline & Range & $3-12$ & $3-12$ & 0.40 \\
\hline & Mean \pm SD & $7.47 \pm 2.15$ & $7.63 \pm 3.11$ & $5 \mathrm{NS}$ \\
\hline & \multicolumn{4}{|c|}{1 month post-operative } \\
\hline & Range & $4-12$ & $4-13$ & 0.10 \\
\hline & Mean \pm SD & $7.27 \pm 2.05$ & $8.13 \pm 3.06$ & $1 \mathrm{NS}$ \\
\hline & \multicolumn{4}{|c|}{3 months post-operative } \\
\hline & Range & $3-12$ & $3-13$ & \multirow{3}{*}{$\begin{array}{l}0.26 \\
2 \mathrm{NS}\end{array}$} \\
\hline & Mean \pm SD & $6.97 \pm 2.36$ & $7.43 \pm 3.23$ & \\
\hline & $\mathrm{P} 2$ & $0.082 \mathrm{NS}$ & $0.063 \mathrm{NS}$ & \\
\hline
\end{tabular}

AFC: Antral Follicular Count, S.D.: Standard Deviation, NS: not statistically significant ( $>0.05$ ), P1: comparison between the two groups at the same time, P2: comparison between preoperative and post-operative count in the same group.

In Table 4, serum AMH, FSH, and E2 were compared. Pre-operative as well as one and three month's postoperative levels were comparable in both groups with no significant differences.

The same hormonal serum levels were also compared within each group, results showed that there were no significant changes between the pre-operative and the post-operative levels at one and three months.

No major complications had occurred in any case of the two studied groups; neither intra- nor post-operative. 
Table 4: Comparison between the two studied groups regarding AMH, FSH, and E2 pre-operatively and at different periods of follow up.

\begin{tabular}{|c|c|c|c|c|}
\hline & & $\begin{array}{l}\text { Group-A } \\
\text { with salpingectomy } \mathbf{n = 3 0}\end{array}$ & $\begin{array}{l}\text { Group-B } \\
\text { without salpingectomy } n=30\end{array}$ & P1 \\
\hline \multirow{10}{*}{ AMH (in ng/mL) } & Pre-opera & & & \multirow{3}{*}{$\begin{array}{l}0.339 \\
N S\end{array}$} \\
\hline & Range & $0.45-3.5$ & $0.9-3.3$ & \\
\hline & Mean \pm SD & $2.03 \pm 0.86$ & $2.11 \pm 0.70$ & \\
\hline & \multicolumn{3}{|c|}{1 month post-operative } & \multirow{3}{*}{$\begin{array}{l}0.387 \\
N S\end{array}$} \\
\hline & Range & $0.12-3.5$ & $0.3-3.46$ & \\
\hline & Mean \pm SD & $1.96 \pm 0.86$ & $2.03 \pm 0.93$ & \\
\hline & \multicolumn{2}{|c|}{3 months post-operative } & & \\
\hline & Range & $0.31-3.5$ & $0.49-3.54$ & \multirow{3}{*}{$\begin{array}{l}0.188 \\
N S\end{array}$} \\
\hline & Mean \pm SD & $1.87 \pm 0.81$ & $2.06 \pm 0.83$ & \\
\hline & $\mathrm{P} 2$ & $0.113 N S$ & $0.265 \mathrm{NS}$ & \\
\hline \multirow{10}{*}{$\begin{array}{l}\text { FSH (in } \\
\mathrm{mIU} / \mathrm{mL} \text { ) }\end{array}$} & Pre-opera & & & \multirow{3}{*}{$\begin{array}{l}0.1683 \\
N S\end{array}$} \\
\hline & Range & $4.2-13.1$ & $4.2-12.5$ & \\
\hline & Mean \pm SD & $9.71 \pm 2.79$ & $9.08 \pm 2.21$ & \\
\hline & \multicolumn{2}{|c|}{1 month post-operative } & & \\
\hline & Range & $4.2-14.3$ & $4.6-15.1$ & \multirow{2}{*}{$\begin{array}{l}0.1686 \\
N S\end{array}$} \\
\hline & Mean \pm SD & $10.20 \pm 2.90$ & $10.91 \pm 2.81$ & \\
\hline & \multicolumn{2}{|c|}{3 months post-operative } & & \\
\hline & Range & $4.7-19$ & $5.2-19.6$ & \multirow{3}{*}{$\begin{array}{l}0.274 \\
N S\end{array}$} \\
\hline & Mean \pm SD & $10.35 \pm 3.33$ & $10.82 \pm 4.24$ & \\
\hline & $\mathrm{P} 2$ & 0.118 & 0.071 & \\
\hline \multirow{10}{*}{$\mathrm{E} 2$ (in $\mathrm{pg} / \mathrm{mL}$ ) } & Pre-opera & & & \multirow{3}{*}{$\begin{array}{l}0.1303 \\
N S\end{array}$} \\
\hline & Range & $9-56$ & $12-56$ & \\
\hline & Mean \pm SD & $31.27 \pm 11.98$ & $35.07 \pm 13.86$ & \\
\hline & \multicolumn{2}{|c|}{1 month post-operative } & & \multirow{3}{*}{$\begin{array}{l}0.311 \\
N S\end{array}$} \\
\hline & Range & $15-77$ & $18-70$ & \\
\hline & Mean \pm SD & $34.70 \pm 15.53$ & $38.73 \pm 17.81$ & \\
\hline & \multicolumn{2}{|c|}{3 months post-operative } & & \multirow{4}{*}{$\begin{array}{l}0.261 \\
N S\end{array}$} \\
\hline & Range & $10-76$ & $15-68$ & \\
\hline & Mean \pm SD & $39.6 \pm 17.85$ & $38.57 \pm 15.66$ & \\
\hline & $\mathrm{P} 2$ & 0.068 & 0.097 & \\
\hline
\end{tabular}

AMH: Anti-Mullarian Hormone. FSH: Follicle Stimulating Hormone. E2: Oestradiol Hormone. S.D.: Standard Deviation. NS: not statistically significant ( $p>0.05)$. P1: comparison between the two groups at the same time. P2: comparison between pre-operative and post-operative levels in the same group.

\section{DISCUSSION}

Ovarian malignancy is a leading cause of cancer deaths in women. Most common type of ovarian malignancy is epithelial ovarian carcinoma, with many current researches suggesting that origin is likely to be from fallopian tubes. ${ }^{1}$

The procedure of prophylactic salpingectomy is currently recommended during hysterectomy for benign lesions, and even as a method for contraception in women seeking tubal sterilization. ${ }^{12}$

Present study aimed at evaluating ovarian function in two groups undergoing hysterectomy with salpingectomy versus hysterectomy with preservation of fallopian tubes.
Age was below 45 years to avoid poor ovarian function prior to menopause. In present study, cases were matched regarding age, body mass index and parity. There was no statistically significant difference in the operative time, signifying that procedure of prophylactic salpingectomy does not prolong the operation in expert hands. The current study showed no statistically significant difference between the study and control group regarding postoperative haemoglobin, showing that prophylactic salpingectomy offers no additional blood loss. Absence of complications among the study group adds to the safety of the procedure.

We have further evaluated ovarian functions by measuring pre-operative $\mathrm{AFC}$, and $\mathrm{AMH}, \mathrm{FSH}$, and $\mathrm{E} 2$ serum levels, as well as at one and three months' postoperative follow-up. Results showed no statistically 
significant differences. This confirms the maintenance of good ovarian function after prophylactic salpingectomy. Maintained good ovarian function is important for prevention of early osteoporosis or cardiovascular complications.

Findley et al studied the same effect of prophylactic salpingectomy on ovarian function, but on a smaller number of cases ( 30 patients, randomized into two groups of 15 patients each). ${ }^{13}$ They evaluated only AMH serum levels 4-6 weeks and 3 months post-operatively, and also found no statistically significant difference.

Similar findings were obtained by Sezik et al who recruited 24 cases randomized into two groups randomized for partial or complete salpingectomy during abdominal hysterectomy. ${ }^{14}$ They evaluated Pre- and postoperative (at 1 and 6 months) serum (FSH), luteinizing hormone (LH), E2 values, ovarian volume estimation by transvaginal ultrasound, and ovarian stromal blood flow Doppler velocimetry.

In contrast, Sezik et al concluded that there were difference in hormonal profile after salpingectomy, however, ovarian blood supply got also impaired, recommending good care to preserve the ovarian blood supply during the procedure.

\section{CONCLUSION}

The current study concludes that the procedure of prophylactic salpingectomy is a simple and safe procedure. It should be implemented as an essential step during hysterectomy in premenopausal women, where oophorectomy is not planned to be performed. It has no short term effects on ovarian functions; yet ovarian blood supply has to be protected by gentle handling and safe manipulation.

\section{Funding: No funding sources} Conflict of interest: None declared

Ethical approval: The study was approved by the Institutional Ethics Committee

\section{REFERENCES}

1. Lozano R, Naghavi M, Foreman K, Lim S, Shibuya $\mathrm{K}$, Aboyans $\mathrm{V}$ et al. Global and regional mortality from 235 causes of death for 20 age groups in 1990 and 2010: a systematic analysis for the Global Burden of Disease Study 2010. Lancet. 2012;380(9859):2095-2128.

2. Moyer VA; U.S. Preventive Services Task Force. Screening for ovarian cancer: U.S. Preventive
Services Task Force reaffirmation recommendation statement. Annal Intern Med. 2012;157(12):900-4.

3. Crum CP, Drapkin R, Miron A, Ince TA, Muto M, Kindelberger DW, Lee Y. The distal fallopian tube: a new model for pelvic serous carcinogenesis. Curr Opinion Obstet Gynecol. 2007;19(1):3-9.

4. Kurman RJ, Shih Ie M. The origin and pathogenesis of epithelial ovarian cancer: a proposed unifying theory. Am J Surg Pathol. 2010;34:433-43.

5. Zheng W, Fadare O. Fallopian tube as main source for ovarian and pelvic (non-endometrial) serous carcinomas. Int $\mathrm{J}$ Clin Experiment Pathol. 2012;5(3):182-6.

6. World Cancer Report 2014. World Health Organization. 2014. Chapter 5.12.

7. Piek JM, van Diest PJ, Verheijen RH. Ovarian carcinogenesis: an alternative hypothesis. InOvarian Cancer Springer, New York, NY.2008:79-87.

8. Burger HG, Hale GE, Dennerstein L, Robertson DM. Cycle and hormone changes during perimenopause: the key role of ovarian function. Menopause. 2008 Jul-Aug;15(4 Pt 1):603-12.

9. Kamal EM. Ovarian performance after laparoscopic salpingectomy or proximal tubal division of hydrosalpinx. Middle East Fertil Soc J. 2013 Mar 31;18(1):53-7.

10. World Medical Association. Declaration of Helsinki: Ethical Principles for Medical Research Involving Human Subjects. JAMA. 2013;310(20):2191-4.

11. Committee on Gynecologic Practice. Salpingectomy for prevention of ovarian cancer. American College of Obstetricians and Gynecologists. Committee opinion number $620 ; 2015$.

12. Fatehpuriya DS, Verma L, Sharma S. Clinicopathological study of hysterectomy in benign lesions: a study of 379 hysterectomies. Int J Reprod Contracept Obstet Gynecol. 2017;6(3):934-8.

13. Findley AD, Siedhoff MT, Hobbs KA, Steege JF, Carey ET, McCall CA et al. Short-term effects of salpingectomy during laparoscopic hysterectomy on ovarian reserve: a pilot randomized controlled trial. Fertil Steril. 2013;100(6):1704-8.

14. Sezik M, Ozkaya O, Demir F, Sezik HT, Kaya H. Total salpingectomy during abdominal hysterectomy: effects on ovarian reserve and ovarian stromal blood flow. J Obstet Gynecol Res. 2007;33(6):863-9.

Cite this article as: Dayem TMA, Badawy AM. Effect of prophylactic salpingectomy on ovarian function in premenopausal women in tertiary referral center. Int J Reprod Contracept Obstet Gynecol 2017;6:4243-7. 